\title{
Licopeno induz parada de ciclo celular e apoptose em linhagem humana de câncer de cólon
}

\section{Lycopene induces cell cycle arrest and apoptosis in human colon cancer cell line}

\author{
Nathalia da Costa Pereira Soares ${ }^{1}$, Felipe Leite Oliveira², Ingrid Eliana Ferreira Belluci ${ }^{3}$, Guilherme de \\ Azevedo Maia ${ }^{4}$, Radovan Borojevic ${ }^{5}$, Anderson Junger Teodoro ${ }^{6}$ \\ ${ }^{1}$ Mestrado em Ciência de Alimentos, Universidade Federal do Rio de Janeiro, UFRJ, Brasil. Professora Substituta da \\ Universidade Federal do Rio de Janeiro, UFRJ, Brasil - Departamento de Farmácia. \\ 2 Professor da Universidade Federal do Rio de Janeiro, UFRJ, Brasil - Instituto de Ciências Biomédicas. \\ ${ }^{3}$ Graduação em Nutrição - Universidade Federal do Estado do Rio de Janeiro, UNIRIO, Brasil. \\ ${ }^{4}$ Mestrado em Ciências Morfológicas, Universidade Federal do Rio de Janeiro, UFRJ, Brasil. \\ ${ }^{5}$ Excellion Biomedical Services, Petrópolis, Rio de Janeiro, Brasil. \\ ${ }^{6}$ Professor da Universidade Federal do Estado do Rio de Janeiro, UNIRIO, Brasil - Escola
}

\begin{abstract}
Resumo
Introdução: O câncer de cólon é um grave problema de saúde pública, sendo uma das principais causas de mortalidade por câncer em todo o mundo. A busca por novas opções terapêuticas para os diferentes tipos de câncer é um dos assuntos de maior interesse na atualidade da pesquisa de compostos bioativos. Possíveis estratégias para a prevenção do câncer podem ser alcançadas utilizando agentes quimiopreventivos, como o licopeno, de modo a reduzir ou eliminar os efeitos deletérios da exposição humana a potenciais carcinógenos. Objetivo: avaliar a influência do licopeno e beta-caroteno sobre a proliferação, ciclo celular e apoptose da linhagem T84 de carcinoma de cólon humano. Metodologia: As células T84 foram cultivadas com DMEM, suplementado com 10\% de soro fetal bovino sob atmosfera com $5 \%$ de $\mathrm{CO} 2$ a 37 으, e incubadas com diferentes concentrações de licopeno e beta-caroteno $(0,5-5 \mu \mathrm{M})$ por períodos de 48 e 96 horas. Para análise da proliferação celular foi utilizado o método do MTT. A análise por citometria de fluxo foi utilizada para avaliar a distribuição das fases de ciclo celular e apoptose. Resultados: mostraram que o licopeno diminuiu a proliferação celular da linhagem T84 após 96 horas de tratamento, com aumento de células na fase G1 e diminuição na fase G2/M, promovendo um aumento no processo de apoptose. Nenhum resultado foi observado em células tratadas com beta-caroteno. Conclusão: Diante dos resultados expostos, a quimioprevenção através da ação do licopeno emerge como um importante instrumento na prevenção e controle do câncer de cólon.
\end{abstract}

Palavras-chave: Neoplasia de colón. Terapêutica. Quimioprevenção.

\begin{abstract}
Background: Colon cancer is a serious public health problem, is a leading cause of cancer mortality worldwide. The search for new therapeutic options for different types of cancer is one of the topics of greatest interest at present the research of bioactive compounds. Possible strategies for cancer prevention can be achieved by using chemopreventive agents, such as lycopene, to reduce or eliminate the deleterious effects of human exposure to potential agents carcinogenic. Objective: The aim of study was to evaluate the influence of lycopene on the proliferation, cell cycle and apoptosis of T84 human colon carcinoma. Methodology: The T84 cells were incubated with DMEM supplemented with $10 \%$ fetal bovine serum under an atmosphere of $5 \% \mathrm{CO} 2$ at $37^{\circ} \mathrm{C}$, and incubated with different concentrations of lycopene (0.5-5 MM) for periods of 48 and 96 hours. For analysis of cell proliferation, we used the MTT method. The analysis by flow cytometry was used to evaluate the distribution of the phases of the cell cycle and apoptosis. Results: The results showed that lycopene reduced the cell proliferation of T84 after 96 hours of treatment, an increase of cells in G1 phase and decrease in G2/M phase, causing an increase in the apoptosis process. No results were observed in cells treated with beta-carotene. Conclusion: The chemoprevention through the action of lycopene emerges as an important tool in the prevention and control of colon cancer. Keywords: Colonic neoplasms. Therapeutics. Chemoprevention.
\end{abstract}

\section{INTRODUÇÃO}

O câncer é considerado um importante problema de saúde pública em países desenvolvidos e em desenvolvimento, sendo ainda importante causa de morte no Brasil e

Correspondência / Correspondence: Nathalia da Costa Pereira Soares. Laboratório de Proliferação e Diferenciação Celular - Instituto de Ciências Biomédicas - Av. Carlos Chagas, 373 - Bloco F. 20 andar - Cidade Universitária, Ilha do Fundão - Rio de Janeiro - RJ. Brasil. 21941-902. Telefone: +55 21 2562-6481 / fax: +55 21 2562-6483

Email: ncpsoares@gmail.com no mundo. As neoplasias malignas constituem-se na segunda causa de morte na população, representando quase $17 \%$ dos óbitos de causa conhecida, notificados em 2007 no Sistema de Informações sobre Mortalidade (1). Estimativas preveem que o número de casos deverá aumentar para $12 \mathrm{mi}-$ Ihões até 2030 (2). No Brasil, dados do Instituto Nacional do Câncer (INCA) relataram a ocorrência de cerca de 489.270 casos novos de câncer, no ano de 2010 (1). Em 2012, estimativas apontaram para uma ocorrência de aproximadamente 518.510 mil novos casos de câncer (3). 
O câncer colorretal é classificado como o terceiro tipo mais comum de câncer no mundo em termos de incidência e mortalidade e sua patogênese, juntamente com a sua quimioprevenção, são atualmente áreas de intensa investigação (4). Embora as causas não sejam completamente compreendidas, é geralmente aceito que o componente genético hereditário, combinado com a baixa ingestão de fibras, frutas e legumes, somados a dietas com elevado teor de gordura, carne vermeIha e processada, estão entre os principais fatores de risco (5-6).

Neste sentido, parece essencial identificar agentes dietéticos que poderiam inibir ou minimizar os fatores indutores das neoplasias. Portanto, uma prevenção primária da dieta poderia desempenhar um papel chave no controle da carcinogênese de cólon humano (7).

Agentes quimiopreventivos podem inibir o desenvolvimento do câncer limitando a exposição a agentes carcinogênicos ou atuando na redução dos estágios de promoção/progressão do tumor (8). Em especial, os agentes de bloqueio da progressão do câncer são inibidores de iniciação do tumor deliberando por mecanismos diferentes que incluem: sequestro das espécies reativas de oxigênio (ROS), modulação do ciclo celular, indução de apoptose, alterações das enzimas de fase I e II do metabolismo carcinogênico e danos no DNA complementar (9).

Como os seres humanos estão expostos normalmente a diversos agentes indutores do câncer, incluindo os obtidos através da dieta, possíveis estratégias para a prevenção do câncer podem ser alcançadas utilizando potenciais agentes quimioprotetores, tais como o licopeno e outros carotenoides, de modo a reduzir e/ou eliminar os efeitos deletérios da exposição humana a potenciais carcinógenos (10). Vários estudos epidemiológicos têm sugerido um papel quimiopreventivo de ação aditivo/sinérgico dos compostos presentes em vegetais, frutas e bebidas lácteas em redução do risco de câncer colorretal (11-12).

A busca por novas opções terapêuticas para os diferentes tipos de câncer é um dos assuntos de maior interesse na atualidade da pesquisa de moléculas vegetais. Diversos trabalhos vêm sendo conduzidos com o intuito de se encontrar extratos vegetais e novas substâncias com atividade inibitória sobre diversos tipos de câncer. Sendo assim, a quimioprevenção é uma estratégia importante, já que a utilização de outras terapias não têm sido eficaz no controle ou na alta incidência ou baixa taxa de sobrevivência de câncer de cólon (13).

Células intestinais humanas cultivadas in vitro representam modelos úteis para estudar os efeitos de carotenoides na barreira entre o mundo exterior e o interior do organismo humano (14). Em um estudo anterior, utilizamos um modelo in vitro consistindo de células de adenocarcinoma de cólon (HT-29), que ainda exibem várias características morfológicas e bioquímicas de células intestinais e que acumulam carotenoides, para investi- gar os possíveis mecanismos antitumorais destes compostos relatados na literatura (15).

Há poucos estudos in vitro avaliando os efeitos benéficos dos carotenoides como agentes quimiopreventivos no processo de carcinogênese no cólon humano. Assim, o objetivo do presente estudo foi avaliar a ação do licopeno e beta-caroteno na modulação de proliferação e ciclo celular em linhagem humana de carcinoma de cólon.

\section{MATERIAIS E MÉTODOS}

\section{Cultura de células e protocolo de tratamento}

A linhagem de carcinoma de cólon humano (T84) foi obtida a partir do Banco de Células da Universidade Federal do Rio de Janeiro, e foi cultivada em meio Dulbecco's suplementado com 10\% FBS e $2 \mathrm{~g} / \mathrm{L}$ tampão HEPES, pH 7,4, sob atmosfera de $5 \%$ de CO2. Para cada experimento, todas as células foram plaqueadas, em 104 células/cm2 em placas de 6 e 96 poços, para as análises de ciclo celular e proliferação celular, respectivamente. Após 24 horas, o meio de cultura foi trocado e as células sofreram incubações com diferentes concentrações de licopeno WS (water soluble) $10 \%$ e beta-caroteno (water soluble) $1 \%$ fornecido pela Roche (Rio de Janeiro, RJ, Brasil) dissolvido em água a $50^{\circ} \mathrm{C}$. Células não tratadas foram incluídas em cada placa. As células foram então incubadas por 48 e 96 horas, com troca de meio a cada 48 horas.

\section{Ensaios de viabilidade e proliferação celular}

A viabilidade celular foi determinada pelos ensaios de MTT (brometo de 3-[4,5-dimetil-tiazol-2-il]-2,5-difenil- tetrazólio) (Amresco, EUA). Depois de tratadas com licopeno e beta-caroteno, em várias concentrações e, incubadas por 48 e 96 horas (05 poços duplicata para cada amostra), $20 \mu \mathrm{L}$ de MTT ( $5 \mathrm{~g} / \mathrm{L}$ ) foi adicionado a cada poço. Após 4 horas de incubação, $100 \mu \mathrm{L}$ por poço de SDS (detergente dodecil sulfato de sódio) foi adicionado para dissolver o formazan produzido. A leitura foi feita em leitor de ELISA no comprimento de onda de $570 \mathrm{~nm}$. A taxa de inibição da proliferação celular (CPIR) foi calculada utilizando a seguinte fórmula: $\mathrm{CPIR}=(1-$ valor médio do grupo experimental / valor médio do grupo controle) $\times$ $100 \%$.

\section{Análise de ciclo celular}

A linhagem celular T84 foi incubada durante 48 e 96 horas na presença e ausência de licopeno e beta-caroteno, e com posterior lavagem rápida em solução salina tamponada (PBS) livre de cálcio e magnésio, e as células foram destacadas com auxílio de tripsina em temperatura ambiente. A suspensão celular foi filtrada e analisada para conteúdo de DNA por citometria de fluxo. As células com conteúdo de DNA inferior aos apresentados na fase $\mathrm{G} 1$ na distribuição do ciclo celular foram contadas como células hipodiplóides (sub-fase G1), que representa a fração de células onde ocorreu fragmentação 
do DNA, característica de morte celular por apoptose (16). As proporções relativas de células com conteúdo de DNA indicativo de apoptose $(<2 n)$, G0-G1 diplóide (2n), S (fase $>2 n$ e $<4 n$ ), e fase G2/M (4n) foram adquiridas e analisadas utilizando CellQuest e WinMDI 2,9, respectivamente. A percentagem de população de células em uma fase específica foi estimada com EXPO32 software de análise V1.2.

\section{Análise Estatística}

Os dados apresentados são médias \pm desvio padrão de três experimentos independentes feitos em triplicata $(n=6)$. Os dados experimentais obtidos foram submetidos à análise de variância (ANOVA) e as médias comparadas através do teste de Tukey ao nível de $5 \%$ de probabilidade, utilizando-se o programa GraphPad Prism 4.0 e Statistical 6.0 .

\section{RESULTADOS}

Ação do licopeno e beta-caroteno na viabilidade celular da linhagem T84

A linhagem de carcinoma de cólon (T84) apresentou crescimento normal não sofrendo influência do veículo (WS) do carotenoide aplicado. Foi testada a captação de licopeno e beta-caroteno com diferentes veículos, tendo sido identificado níveis de absorção de licopeno e beta-caroteno superiores em células incubadas com meio contendo uma formulação de licopeno solúvel em água (WS), do que em células incubadas com meio contendo licopeno em diferentes solventes orgânicos. No caso do beta-caroteno, a melhor captação ocorreu na mistura do carotenoide em água:etanol (1:1) (dados não mostrados). Estudos anteriores relataram que o licopeno formulado $10 \%$ (WS) não é tóxico e sua formulação com antioxidantes, impede a degradação do licopeno, sendo ainda acumulado no fígado (17).

Após 48 horas de incubação com licopeno, foi observada uma diminuição da proliferação celular em todas as concentrações de licopeno utilizadas $(0,5-5 \mu \mathrm{M})$, não havendo diferença estatística entre as doses ( $p>0,05)$, e com percentual de inibição médio em torno de $28 \%$ (Figura 1). As concentrações mais baixas de licopeno $(0,5-1,0 \mu \mathrm{M})$, semelhantes àquelas encontradas na corrente sanguínea de uma pessoa sadia, promoveram a mesma alteração no perfil de crescimento da linhagem T84, comparadas às doses mais altas obtidas por suplementação de licopeno (Figura 1).

Somado a isso, após 96 horas de tratamento com licopeno, foi possível constatar novamente um potente efeito inibitório no crescimento da linhagem T84 em todas as doses aplicadas (Figura 1). A taxa de redução na viabilidade celular foi semelhante neste tempo de tratamento (média de $26 \%$ de inibição), não havendo diferença estatística entre as diversas doses e entre os tempos de tratamento $(p>0,05)$.

Entretanto, não foi possível observar nenhuma alteração na taxa de crescimento celular na comparação
Figura 1. Perfil de crescimento celular da linhagem de carcinoma de cólon (T84) incubada com diferentes concentrações de licopeno $(0,5-5 \mu \mathrm{M})$ por diferentes intervalos de tempo (4896 horas). Os dados são apresentados como médias $\pm S D, n=3$, $* p<0,05$ versus grupo controle.

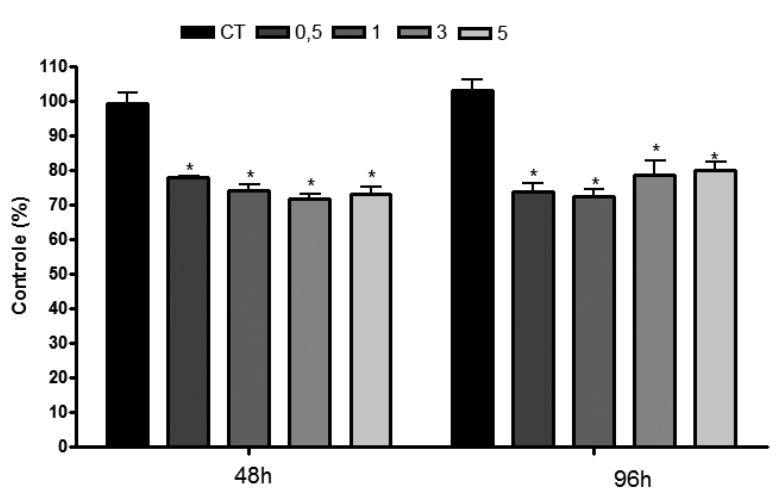

entre as células controle e as tratadas com beta-caroteno, independentemente da dose utilizada e/ou tempo de exposição ao carotenoide (Figura 2).

Licopeno na modulação do ciclo celular e apoptose

Figura 2. Perfil de crescimento celular da linhagem de carcinoma de cólon (T84) incubada com diferentes concentrações de beta-caroteno $(0,5-5 \mu \mathrm{M})$ por diferentes intervalos de temf po (48-96 horas). Os dados são apresentados como médias \pm $S D, n=3, * p<0,05$ versus grupo controle.

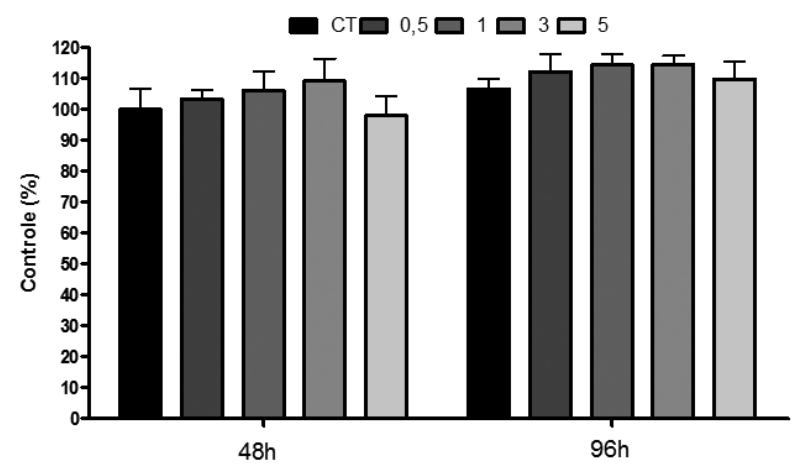

Para avaliação da influência do licopeno e beta-caroteno na progressão do ciclo celular e apoptose da linhagem de carcinoma de cólon humano (T84), foi realizado um tratamento da linhagem durante 48 e 96 horas com licopeno e beta-caroteno, sendo posteriormente quantificado o percentual de células nas diferentes fases do ciclo celular e o percentual de células apoptóticas por citometria de fluxo.

Inicialmente, foi observado que o licopeno $(5 \mu \mathrm{M})$ aumentou o percentual de células da linhagem T84 na fase G0/G1, após 48 horas de incubação. No entanto, nenhuma alteração foi observada nas outras fases do ciclo celular, independentemente da dose utilizada (Figura 3A). Foi possível verificar ainda que o licopeno promoveu modificações importantes na progressão do ciclo celular da linhagem T84 após 96 horas de trata- 
mento. Em relação ao ciclo celular, constatou-se um aumento de células na fase G0/G1, com respectiva diminuição de células na fase $\mathrm{G} 2 / \mathrm{M}$ pela ação do licopeno, sendo o efeito dose-dependente $(p<0,05)$ (Figura 3B).

Corroborando com os dados de proliferação celular, não foi identificada nenhuma alteração na distribuição das células nas diferentes fases do ciclo celular, quando as mesmas sofreram tratamento com beta-caroteno por 48 e 96 horas (dados não mostrados).

$\mathrm{Na}$ avaliação do processo de apoptose induzida pelo licopeno, foi verificado um aumento do percentual de células apoptóticas com taxa de aumento relativo de 1,2 vezes quando comparado ao grupo não tratado nas concentrações mais altas ( 3 e $5 \mu \mathrm{M}$ ) após 48 horas de tratamento. Somado a isso, após 96 horas de incubação com licopeno foi possível observar um importante aumento no percentual de células apoptóticas, com aumento mínimo e máximo de $32 \%$ e $80 \%$, respectivamen- te, com diferença estatística $(p<0,05)$ entre as doses utilizadas, indicando um efeito tempo e dose-dependente (Figura 4). Nenhuma alteração no processo de apoptose foi observada nas células incubadas com beta-caroteno (Figura 4).

\section{DISCUSSÃO}

O presente estudo demonstrou o efeito do licopeno na modificação do perfil de crescimento celular da linhagem de carcinoma de cólon humano (T84), com parada de ciclo celular na fase G0/G1, somado a um aumento de células apoptóticas.

Existem vários mecanismos pelos quais o tomate, seus produtos e, particularmente o licopeno exercem inibição da carcinogênese, sendo os principais descritos pela literatura: a eliminação de espécies reativas de oxigênio, o aumento de sistemas de desintoxicação, a supressão da progressão do ciclo celular, bem como modu-

Figura 3. Efeito do licopeno na progressão do ciclo celular de carcinoma de cólon após 48 horas (A) e 96 horas (B). O experimento é expresso em média \pm desvio padrão, sendo diferenças significativas entre as células não tratadas (CT) e as tratadas com licopeno (1-5 $\mu \mathrm{M})$ comparadas pelo teste de Tukey $\left({ }^{*} p<0,05 ;{ }^{* *} p<0,01\right.$; $* * * p<0,001)$.
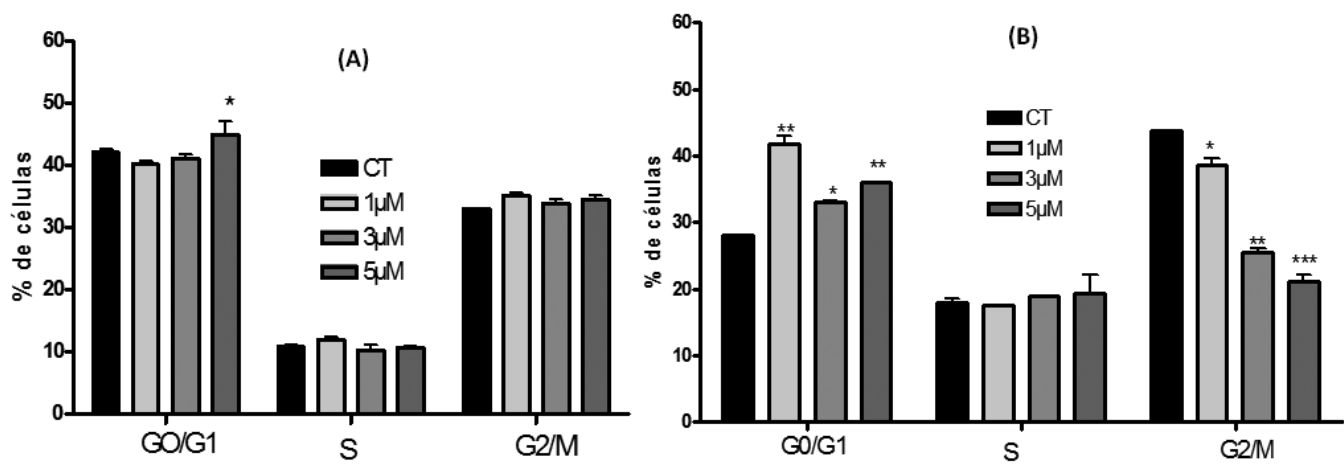

Figura 4. Taxa de aumento relativo de células em apoptose da linhagem T84 tratada com licopeno e beta-caroteno após 48 e 96 horas. Comparação relativa entre células não tratadas (CT) e células incubadas com lico-

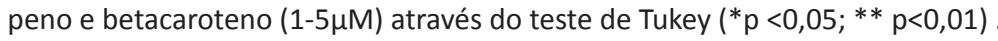

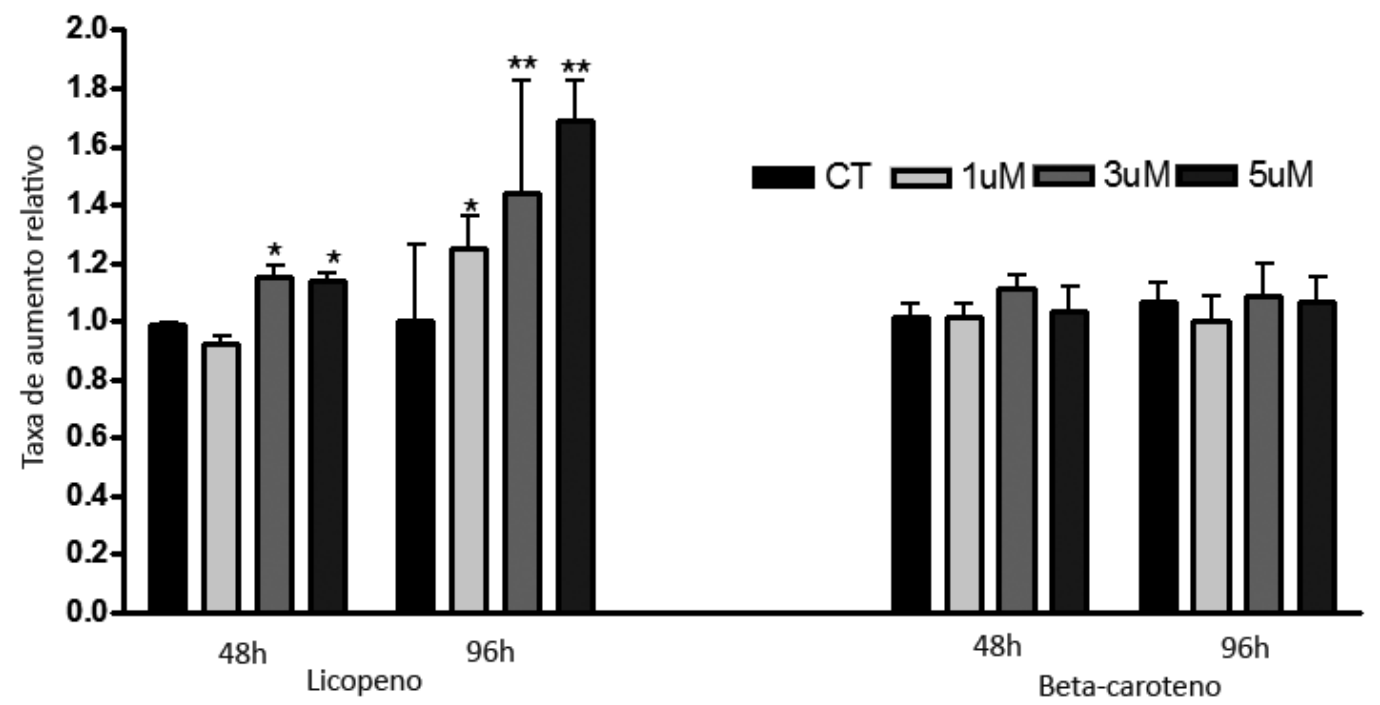


lação das vias de transdução de sinal $(18,19)$. A atividade antioxidante do licopeno tem sido extensivamente estudada $(20,21)$, sendo o seu efeito melhorado pela adição de outros antioxidantes $(22,23)$.

No estudo dos efeitos do licopeno sobre o crescimento de células cancerosas, já foi relatado que o tomate maduro, contendo essencialmente o licopeno, é um agente antiproliferativo, não só em células de câncer da próstata (24), mas também em linhagens de câncer do cólon, tais como HT-29 (15). Estudos recentes demonstraram que linhagens celulares de câncer de cólon não foram afetadas na sua viabilidade pela ação do licopeno (25-26). Em nosso trabalho foi observada pela primeira vez uma inibição da proliferação celular na linhagem T84, após 48 e 96 horas de tratamento com licopeno, sendo os resultados diferentes de outros trabalhos já descritos na literatura. Além disso, foi possível constatar que doses fisiológicas podem exercer um efeito antiproliferativo, indicando um possível efeito preventivo do licopeno no câncer de cólon (27).

A desregulação no controle do ciclo celular é um aspecto fundamental no desenvolvimento do câncer. As células normais apenas proliferam em resposta ao desenvolvimento da célula ou a sinais presentes na mitose que indicam um requisito para o crescimento do tecido, enquanto que a proliferação das células cancerosas procede essencialmente sem controle. Isto indica que as células cancerosas proliferam devido a presença de defeitos de sinalização internos e/ou externos (28). Estudos anteriores mostram que o licopeno $(29,30)$ ou extratos de licopeno (25) induziram parada do ciclo celular na fase G0/G1 devido a baixa regulação de ciclinas, incluindo ciclina E e ciclina D1 $(25,31-32)$ e/ou pela regulação positiva de ciclina A e p27 (31).

De acordo com Hirsh e cols. (33), os carotenoides, incluindo licopeno, são capazes de suprimir a proliferação de células malignas através da inibição da atividade estrogênica da 17-beta-estradiol e genisteína, um fitoestrógeno hormônio-dependente, em células cancerosas. A inibição do crescimento celular mostrada parece ser mediada por atenuação de progressão do ciclo celular da fase G1 para a fase S. Por outro lado, Nahum e cols. (34) têm sugerido mecanismos adicionais para explicar o efeito inibitório de licopeno na proliferação das células do câncer, que incluem a sua capacidade para atenuar o fator de crescimento semelhante à insulina, e a inibição da progressão do ciclo na fase G0/G1.

Em nosso trabalho o licopeno foi capaz de modular o ciclo celular, promovendo aumento do percentual de células na fase G0/G1, com respectiva diminuição na fase $\mathrm{G} 2 / \mathrm{M}$, semelhante ao ocorrido em outros trabaIhos. Estas observações sugerem que o licopeno pode alterar proteínas reguladoras do ciclo celular, dependendo da dose e do tempo de administração deste composto.

Apesar da enorme variabilidade do câncer, evidências demonstram que a resistência à apoptose é uma das características mais marcantes da maioria dos tumores malignos (35). Na prática clínica, a apoptose é alvo para um potencial uso terapêutico da morte celular programada, sendo a compreensão dos mecanismos e das alterações nos componentes das vias apoptóticas, e sua correlação com a ocorrência do câncer, ferramentas importantes para o desenvolvimento de novas terapias e métodos de prevenção do câncer (36-37).

$\mathrm{O}$ efeito quimiopreventivo do licopeno mediada pela sua capacidade para induzir a apoptose já foi descrito anteriormente por outros trabalhos (38-39). Estes sugerem que a ação apoptótica dos carotenoides pode depender da formação intracelular de produtos auto-oxidantes, a partir do tratamento com o licopeno (40).

Como a apoptose é o ponto final de pelo menos uma das vias de diferenciação das células epiteliais do cólon, um processo que resulta em morte celular por apoptose também deve minimizar o sinal proliferativo. De fato, em nosso modelo, o aumento da taxa de morte celular por apoptose, após 96 horas de incubação com licopeno, foi acompanhado por um aumento de células na fase G0/G1 do ciclo celular.

\section{CONCLUSÃO}

Diante dos resultados expostos, a quimioprevenção através da ação do licopeno emerge como um importante instrumento na prevenção e controle do câncer de cólon, sugerindo mecanismos de ações anticarcinogênicos e antioxidantes, que podem auxiliar contra a progressão e/ou desenvolvimento do câncer de cólon.

\section{REFERÊNCIAS}

1. BRASIL. Ministério da Saúde.Instituto Nacional do Câncer. Estimativa 2010: incidência de câncer no Brasil. Rio de Janeiro: INCA, 2009 Disponível em: <http://www.inca.gov.br/estimativa/2010/index. asp?link=conteudo_view.asp\&ID=2>.

2. WORLD HEALTH ORGANIZATION. WHO programmes and projects: cancer. Disponível em: <http://www.who.int/cancer/en/. 2010>.

3. BRASIL, Ministério da Saúde, Instituto Nacional do Câncer. Estimativa 2012: incidência de câncer no Brasil. Rio de Janeiro: INCA, 2012. Disponível em: <http://www.inca.gov.br/estimativa/2012/index. asp?ID=2>.

4. SEGAL, N.H., SALTZ, L.B. Evolving treatment of advanced colon cancer, Annu. Rev. Med., Palo Alto, v.60, p.207-219. feb. 2009

5. LIEBERMAN, D.A. et al. Risk factors for advanced colonic neoplasia and hyperplastic polyps in asymptomatic individuals. Jama, Chicago, v.290,n.22, p.2959-2967, dec. 2003.

6. JO, W.S.; CHUNG, D.C. Genetics hereditary colorectal cancer. Semin. Oncol., New York, vol.23,no.1, p.11-23, fev. 2005.

7. MASON, J.B. Nutritional chemoprevention of colon cancer. Semin. Gastrointest. Dis., Philadelphia, v.13, n.3, p.143-153, jul. 2002.

8. MOURA, N.A. Efeitos da ingestão de Yacon (Polymnia sonchifolia) sobre o processo de carcinogênese de cólon induzido pela 1, 2-dimetilhidrazina em ratos Wistar. 2012. . 76 f. Dissertação (Mestrado) Programa de Pós-Graduação em Biologia Geral e Aplicada, Instituto de Biociências, Universidade Estadual Paulista. 2012. 
9. STONER, G.D.; MORSE, M.A.; KELLOFF, G. Perspective in cancer chemoprevention. Environ. Health Perspect, Research Triangle Park, v.105, suppl. 4, p.945-954, jun.1997.

10. SUGIMURA, T. Nutrition and dietary carcinogenesis. Carcinogenesis, Oxford, v.21, n.3, p.387-395, sep.2000.

11. TAKAHASHI, H. et al. Time spent walking and risk of colorectal cancer in Japan: the Miyagi Cohort study. Eur. J. Cancer Prev., Oxford, v.16, n. 5, p.403-408, oct. 2007.

12. MURTAUGH, M.A. et al. Antioxidants, carotenoids, and risk of rectal cancer. Am. J. Epidemiol., Baltimore, v.159, n. 1, p.32-41, jan. 2004.

13. GUSTIN, D.M.; BRENNER, D.E. Chemoprevention of colon cancer: current status and future prospects. Cancer Metastasis Rev., Boston, v.21, n. 3-4, p.323-348, 2002

14. RANALDI, G. et al. Beneficial or detrimental effects of carotenoids contained in food: cell culture models. Mini Rev. Med. Chem., Hilversum, v.7, n. 11, p.1120-1128, nov. 2007.

15. BOROJEVIC, R. et al. Influência dos carotenoides na proliferação e ciclo celular de linhagem celular de adenocarcinoma de cólon humano. Rev. Soc. Bras. Concerol., Salvador, v.12I, n.43, p.152-153. 2010.

16. AMARANTE-MENDES, G.P. et al. Cell: A Laboratory Manual. U.S.A.: Cold Spring Harbor Laboratory, 1997. 2136 p.

17. MCCLAIN, M.; BAUSCH, J. Summary of safety studies conducted with synthetic lycopene. Regul. Toxicol. Pharmacol., New York, v.37, n.2, p.274-285. april 2003.

18. BHUVANESWARI, V.; NAGINI, S. Lycopene: a review of its potential as an anticancer agent. Curr. Med. Chem. Anticancer Agents, Hilversum, v.5, n.6, p.627-635. november 2005.

19. HEBER, D.; LU, Q.Y. Overview of mechanism of action of lycopene. Exp. Biol. Med., Maywood, v.227, n.10, p.920-923. november 2002.

20. RAO, A.V. Processed tomato products as a source of dietary lycopene: bioavailability and antioxidant properties. Can. J. Diet. Pract. Res., Markham, v.65, n.4, p.161-165. Winter 2004.

21. AGARWAL S, RAO AV. Tomato lycopene and its role in human health and chronic diseases. CMAJ, Ottawa, v.163, n. 6, p.739-744. september 2000.

22. SATO, R. et al. Prospective study of carotenoids, tocopherols, and retinoid concentrations and the risk of breast cancer. Cancer Epidemiol. Biomarkers. Prev., Philadelphia, v.11, n.5, p.451-457. May 2002.

23. LIMPENS, J. et al. Combined lycopene and vitamin E treatment suppresses the growth of PC-346C human prostate cancer cells in nude mice. J. Nutr., Springfield, v.136, n. 5, p.1287-1293. May 2006.

24. SILVA, A.M.; SCHNEIDER, V.C.; PEREIRA, C.A.M. Propriedades químicas e farmacológicas do licopeno. REF, Goiania, v.6, n.2, p.36-61. 2009.

25. PALOZZA, P. et al. The growth-inhibitory effects of tomatoes digested in vitro in colon adenocarcinoma cells occur through down regulation of cyclin D1, Bcl-2 and Bcl-xL. Br. J. Nutr., London, v.98, n.4, p.789795, oct. 2007.
26. SAMBUY, Y. et al. The Caco- 2 cell line as a model of the intestinal barrier: influence of cell and culture-related factors on Caco-2 cell functional characteristics. Cell Biol. Toxicol., Princenton NJ, v.21, n.1, p.1-26, jan.2005.

27. YANG, Z. et al. Serum carotenoid concentrations in postmenopausal women from the United States with and without osteoporosis. Int. J. Vitam. Nutr. Res., Bern, v.78, n. 3, p.105-111, may 2008.

28. NAKAYAMA, K.I. et al. Ubiquitin ligases: cell-cycle control and cancer. Nat. Rev. Cancer., London, v.6, n.5, p.369-381, may 2006.

29. OBERMÜLLER-JEVIC, U.C. et al. Lycopene inhibits the growth of normal human prostate epithelial cells in vitro. J. Nutr., Springfield, v.133, n. 11, p.3356-3360, nov. 2003.

30. HWANG, E.S.; BOWEN, P.E. Effects of tomato paste extracts on cell proliferation, cell-cycle arrest and apoptosis in LNCaP human prostate cancer cells. Biofactors., Oxford, v.23, n.2, p.75-84. 2005.

31. NAHUM, A. et al. Lycopene inhibition of cell cycle progression in breast and endometrial cancer cells is associated with reduction in cyclin D levels and retention of p27(Kip1) in the cyclin E-cdk2 complexes. Oncogene, Basingstoke, v.20, n.26, p.3428-3436, Jun.2001.

32. TANG, F.Y. et al. Lycopene inhibits growth of human colon cancer cells via suppression of the Akt signaling pathway. Mol. Nutr. Food Res.,Weinheim, v.52, n. 6, p.646-654, jun.2008.

33. HIRSCH, K. et al. Lycopene and other carotenoids inhibit estrogenic activity of 17 beta-estradiol and genistein in cancer cells. Breast Cancer Res. Treat., Boston, v.104, n.2, p.221-230, aug.2007.

34. NAHUM, A. et al. Lycopene inhibition of IGF-induced cancer cell growth depends on the level of cyclin D1. Eur. J. Nutr., Darmstadt, v.45, n.5, p.275-282, aug. 2006 .

35. OKADA, H.; MAK, T.W. Pathways of apoptotic and non-apoptotic death in tumour cells. Nat. Rev. Cancer, London, v.4, n. 8, p.592-603, aug.2004.

36. NICHOLSON, D.W. From bench to clinic with apoptosis-based therapeutic agents. Nature, London, v.407, n. 6805, p.810-16, oct. 2000.

37. DEBATIN, K.M. Apoptosis pathways in cancer and cancer therapy. Cancer Immunol. Immunother., Berlim, v.53, n.3, p.153-59, mar.2004.

38. CHALABI, N. et al. Expression profiling by whole-genome microarray hybridization reveals differential gene expression in breast cancer cell lines after lycopene exposure. Biochim. Biophys. Acta, Berlim, v.1769, n.2, p.124-130, fev. 2007.

39. IVANOV, N.I. et al. Lycopene differentially induces quiescence andapoptosis in androgen-responsive and -independent prostste cancer cell lines. Clin. Nutr., Edinburgh, v.26, n.2, p.252-263,apr.2007.

40. ZHANG, H. et al. A novel cleavage product formed by autoxidation of lycopene induces apoptosis in HL-60 cells. Free Radic. Biol. Med., New York, v.35, n.12, p.1653-1663, Dec. 2003.

Submetido em 29.03.2013;

Aceito em 20.08.2013. 